\title{
O Uso de Indicadores Ambientais no Acompanhamento de Sistemas de Gerenciamento Ambiental
}

\section{Marco Antonio Gaya de Figueiredo}

Engenheiro de Processo III Petrobras / Cenpes / Dipol / Grudep

Ilha do Fundão - Quadra 07 - Cidade Universitária

Rio de Janeiro -RJ - CEP 21494-900

Palavras-chave: Indicadores Ambientais, Gerenciamento Ambiental

Key Words: Environmental performance indicators, Environmental Management

\section{RESUMO}

Este trabalho visa apresentar a utilização de indicadores de performance ambiental no acompanhanento do gerenciamento ambiental. Sob este enfoque será apresentada uma visão geral dos sistemas de gerenciamento ambiental e dos atuais tipos de indicadores estudados. Como conclusão será apresentada uma visão de füturo referente ao gerenciamento ambiental.

\section{ABSTRACT}

Process environmental performance evaluation is practiced by many industries, aiming to establish adequate environmental conditions, and to create a methodology for eliminating critical points from the productive process. This work describes the follow-up of environmental management through a selection of environmental performance indicators. A general review of environmental manegement systems is presented together with the most common used indicators. In conclusion, a future view of environmental manegement is discussed. 


\section{PRODUÇÃO}

\section{Introdução}

O gerenciamento ambiental, conforme apresentado na literatura [Weibe, 1994] envolve atuações em três áreas, a saber:

(1) Poluição do meio ambiente.

(2) Conservação de recursos (reciclagem / re-uso)

(3) Saúde e segurança das pessoas

No primeiro caso encontramos as emissões, descargas de efluentes que geram perturbação no meio ambiente (local, regional e global); no segundo, aspectos relacionados com flora e fauna, recursos naturais. O último está correlacionado com todos os efeitos na sociedade.

Quanto às tendências observa-se que a poluição ambiental ainda continua sendo um grande problema em determinadas regiões. No caso da conservação de recursos ainda representa um grande desafio para os países industrializados; na área de segurança e saúde observa-se uma crescente preocupação da sociedade refletindo no aumento do rigor das legislações não apenas ambientais mas em todas as áreas, tais como: proteção do consumidor, segurança dos alimentos, pesticidas, produtos químicos, organismos perigosos, produtos perigosos, defeitos e acidentes, entre outras.

\section{1- Sistemas de Gerenciamento Ambiental}

O gerenciamento ambiental de um processo está voltado para o contexto do homem em seu habitat. Dentro desta abordagem, o identificamos como sendo uma atividade integrada de forma que, para termos uma performance ambiental dentro dos padrões estabelecidos tanto pela legislação relativa ao meio ambiente como pela legislação trabalhista devemos, basicamente, atender aos seguinte princípios:

\section{Internamente ao processo}

Treinar - Assegurando o perfeito entrosamento dentro do processo

Manter vigilância nos sistemas Permitindo o trabalho em condições seguras

Manter ambiente limpo e seguro Garantindo a saúde dos técnicos

\section{Externamente ao processo}

Tratar efluentes - Garantindo a qualidade dos recursos naturais (água, ar e solo).

Informar - Garantindo à população o nivel de risco da atividade desenvolvida

Monitorar sistemas externos Evitando danos ambientais

Minimizar impacto ambiental Desenvolvendo atividades visando eliminar ou minimizar os rejeitos industriais

Dentro desta ótica, diversas são as linguagens a serem apresentadas pelos responsáveis pelo gerenciamento ambiental para expressar a performance ambiental do processo, ou seja:

Para o tomador de decisão - Envolvimento financeiro com a atividade 
Para os técnicos - Situação do processo como um todo

Para a comunidade - Desempenho do processo quanto às externalidades

Como exemplo de balizadores para estas informações normalmente os seguintes parâmetros são utilizados: custo por lucro operacional, ocorrências operacionais por tempo e número de acidentes por tempo.Para cada caso existem vantagens e desvantagens conforme apresentado no quadro abaixo. regulamentações impostas pelos órgão fiscalizadores. $O$ esforço neste caso está em alcançar os requisitos para saúde, segurança e meio ambiente estabelecidos na lei.

\section{Estágio (2): Desenvolvimento e implementação de sistemas}

Neste estágio encontramos empresas com sistemas formais de gerenciamento ambiental, os quais elaboram métodos para atendimento às legislações e também identificam oportunidades que geram

\begin{tabular}{|l|l|l|}
\hline \multicolumn{1}{|c|}{ Parâmetro } & \multicolumn{1}{|c|}{ Vantagem } & \multicolumn{1}{|c|}{ Desvantagem } \\
\hline Custo por lucro & $\begin{array}{l}\text { Nível de perdas do } \\
\text { processo }\end{array}$ & $\begin{array}{l}\text { Não identifica os principais } \\
\text { responsáveis }\end{array}$ \\
\hline Ocorrências por tempo & $\begin{array}{l}\text { Nível de operosidade da } \\
\text { unidade }\end{array}$ & $\begin{array}{l}\text { Não mostra os principais } \\
\text { pontos de falla }\end{array}$ \\
\hline Acidentes por tempo & $\begin{array}{l}\text { Nível de segurança da } \\
\text { unidade }\end{array}$ & $\begin{array}{l}\text { Não mostra os riscos } \\
\text { internos do processo }\end{array}$ \\
\hline
\end{tabular}

Dentro deste panorama, a depender do porte da empresa, verificamos o grau de dificuldade ell acompanhar de maneira sistemática e uniforme o desempenho ambiental do processo. De uma forma geral, o gerenciamento ambiental pode ser identificado em cinco estágios a saber:

\section{Estágio (0) : Sem gerenciamento}

Neste segmento encontramos as empresas que acreditam não apresentar interferências no meio ambiente tanto interno e externo ao processo.

\section{Estágio (1): Atendimento à legislação}

Neste estágio as empresas contemplam uma politica de atendimento às ganhos tanto em termos de custos como em beneficios ambientais.

\section{Estágio (3) : Integração com as} diversas áreas gerenciais

Empresas que além de possuir sistema formal de gerenciamento ambiental, o mantém integrado com as demais funções de forma que todas as atividades considerem os aspectos ambientais (desenvolvimento, produção, descartes, estratégia de mercado etc.).

Estágio (4) : Integração com qualidade total

Neste contexto, o sistema de gerenciamento ambiental é aplicado a 


\section{PRODUÇÃO}

todas as operações de forma global, sendo continuamente avaliado para aproveitamento das oportunidades (tecnologias de ponta, alterações de práticas gerenciais etc...). Neste estágio esforços são dirigidos para identificação completa do ciclo de vida dos produtos, serviços, operações incluindo efeitos diretos, indiretos e secundários no meio ambiente.

\section{2- A Avaliação do Desempenho Ambiental}

\section{1- Aspectos Gerais}

Em termos históricos [David J.Rapport, 1990], podemos, de uma forma suscinta, observar a seguinte evolução:
Conforme apresentado no artigo "Environmental information for all. The need for a montly index" [Hope and Parker, 1990], o sucesso observado e a larga aceitação de indices econômicos no periodo pós guerra inspirou considerável interesse, no final dos anos 60 , em formas para desenvolver indices que identificassem a qualidade do meio ambiente.

Dentre as principais finalidades encontradas no acompanhamento quantitativo de um processo, via utilização de um indice de desempenho ambiental, encontramos:

- Monitoramento do estado do meio ambiente e da sua evolução ao longo do tempo

\begin{tabular}{|c|l|l|l|}
\hline FASE & \multicolumn{1}{|c|}{ PERÍODO } & \multicolumn{1}{|c|}{ OBSERVAÇÕES } & INDICADORES \\
\hline Primeira onda & sec 17/18 & $\begin{array}{l}\text { Poluição em rios } \\
\text { navegáveisMortandade de } \\
\text { peixesOdores }\end{array}$ & $\begin{array}{l}\text { Evidentes e facilmente } \\
\text { identificáveis (coloração } \\
\text { etc..) }\end{array}$ \\
\hline Segunda onda & anos 50/70 & $\begin{array}{l}\text { Efeitos tóxicos e } \\
\text { deformidades em espécies } \\
\text { sensíveisIntegridade } \\
\text { ambiental }\end{array}$ & $\begin{array}{l}\text { Sinais pré-clínicos ou } \\
\text { sintomas de desequilíbrio } \\
\text { de ecossistemas. Foco } \\
\text { central na pureza da } \\
\text { natureza, na. integridade } \\
\text { do ecossistema }\end{array}$ \\
\hline Terceira onda & Atual & $\begin{array}{l}\text { Medidas integradas das } \\
\text { transformações ecológicas } \\
\text { dentro do contexto das } \\
\text { alterações culturais e } \\
\text { sócio econômicas }\end{array}$ & $\begin{array}{l}\text { Espécies biológicas em } \\
\text { extinção. }\end{array}$ \\
\hline
\end{tabular}




\section{PRODUÇÃO}

- Avaliação da performance dos projetos, programas e planos

- Controle gerencial do processo visando melhorias no processo

- Demonstração ao público e a outros interessados na melhoria contínua dos produtos e processos

- Auxílio no desenvolvimento de planos futuros

Como características para indicadores de desempenho, segundo apresentado no informativo da Associação Brasileira das Indủstrias Quimicas [ABIQUIM, 1994], encontramos:

\begin{tabular}{|c|c|}
\hline ASPECTOS & CARACTERISTICAS \\
\hline simplicidade & 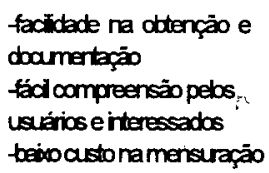 \\
\hline Uifidade & 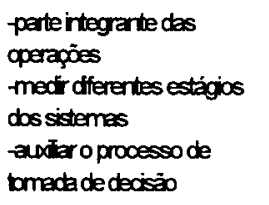 \\
\hline crectbidade & 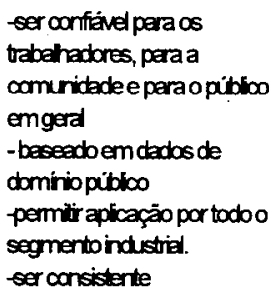 \\
\hline
\end{tabular}

\section{2- Aplicação de Indicadores de Desempenho}

Observando-se a tendência atual em termos de desenvolvimento industrial, verifica-se que as empresas estão em busca do desenvolvimento sustentável, ou seja, a eliminação de qualquer aspecto ambiental que interfira no desenvolvimento das futuras gerações, balanceando suas considerações econômicas com as ambientais e sociais conforme representado pela figura (1) abaixo:

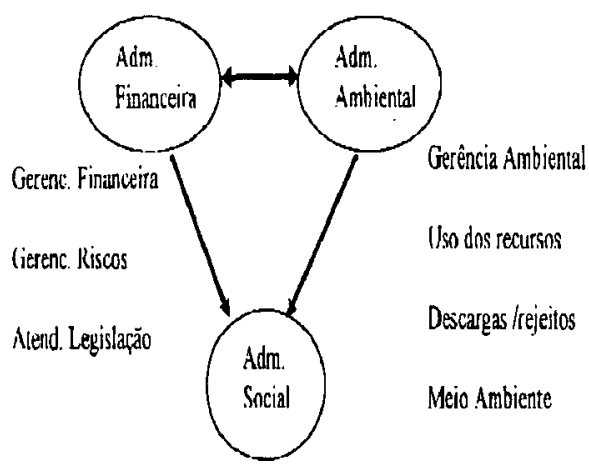

Bcn estar, soúde e segurança

Figura 1 - Representação esquemática da integraçāo das áreas enu um processo

Em função desta tendência, verificase que a principal razão para informar a performance ambiental é a de comunicar diversos aspectos destas administrações relacionadas com o meio ambiente.

A aplicação de indicadores, de um modo geral, reflete a necessidade da quantificação de parâmetros que penmitam avaliar, da forma mais correta possivel, a eficiência e eficácia do processo produtivo. 


\section{PRODUÇÃO}

Analisando os diversos indicadores de desempenho utilizados em diversos processos produtivos, verificamos a existência de indicadores que medem etapas intermediárias do processo e os que representam o resultado final de todo o sistema (físico ou gerencial). A complexidade no indicadores decorre da complexidade dos pontos controlados e por vezes também da etapa do processo ao qual ele está relacionado.

Desta forma, conforme apresentado pela $A B I Q U I M$ na área de indicadores para o Processo de Atuação Responsável, podemos identificar os seguintes tipos de indicadores[ABIQUIM, 1994]:

SISTEMICOS - Acompanham medidas ou índices dentro dos sistemas. São indicadores simples (quando envolvem medidas ou índices não relacionados a outros) ou complexos (quando relacionados em série a medidas ou outros índices)

FINAIS - Representam ao resultado final de todo um acompanhamento

Em termos de padronização a nível internacional, acompanhando a atual série de normas ambientais (Normas ISO 14000), encontramos no item relacionado à avaliação da performance ambiental [ISO/TC207/SC4 WD 14031.1] a seguinte proposição quanto aos indicadores de performance ambiental. devem:

Quanto à utilização os indicadores

- Assegurar una avaliação compreensiva dos aspectos ambientais

- Levar à identificação de aspectos críticos e relevantes da performance ambiental

Quanto às áreas de avaliação de performance ambiental encontramos indicadores relativos $\mathrm{a}$ :

- Sistemas gerenciais - identificando pontos fortes ou fracos na organização

- Sistemas operacionais - cargas decorrentes do processo para o meio ambiente

- Estado do meio ambiente - condição do meio ambiente no momento da avaliação

\section{3 - Tipos de Indicadores}

Efetuando um levantamento da literatura disponivel relativa a indicadores de performance ambiental encontramos:

\section{1-Indicadores de Sistemas Operacionais}

Sistema operacional é definido como o conjunto de atividades relacionadas com o projeto e a operação de plantas físicas, equipamentos e fluxos de massa e energia necessários para a geração de produtos e serviços. Em termos de estudos para identificação de indicadores para esses sistemas encontramos as seguintes categorias[API. 1994].

Medidas orientadas por programas -A simples existência de programas para prevenção ou minimização de efluentes já contém elementos específicos que quantificam a redução, servindo como um elemento desta categoria.

Medidas baseadas em atividades Indicadores baseados em medidas semi quantitativas de esforços relativos a equipamentos ou procedimento em uso. 
Neste segmento faz-se necessário ter informações específicas sobre os possiveis benefícios das medidas, como por exemplo, uso de tintas isentas de solvente ou aplicação de agitadores em tanque de estocagem para evitar decantação de sólidos.

\section{Medidas baseadas em massa-} Indicadores baseados em informações quantitativas (mesmo estimadas por modelagem matemática) do material produzido (rejeito ou descarte). Como exemplos temos o volume de efluente tratado, total de rejeito sólido movimentado, etc...

\section{Medidas de eficiência normalizada -} Neste segmento relacionamos uma variável a outro item, podendo efetuar comparações em unidades de portes distintos e determinando a eficiência das respectivas práticas de determinada atividade. Como métodos de normalização podemos ter: por atividade/operação, por produção ou por geração residual.

Medidas baseadas em concentração São indicadores tipicamente expressos em unidades de peso por volume ou capacidade (ex: $\mathrm{mg} / \mathrm{kg}, \mathrm{mg} / \mathrm{ml}, \mathrm{mg} / \mathrm{cm}^{3}$ ). Como exemplo temos carga poluente de efluente hídrico $\left(\mathrm{g} / \mathrm{m}^{3}\right)$.

De uma forma compilada, o quadro abaixo apresenta as principais vantagens e desvantagens dos métodos acima apresentados:

Como exemplo destes indicadores no

\begin{tabular}{|c|c|c|c|}
\hline $\begin{array}{l}\text { Medição } \\
\text { Baseado em } \\
\text { programa } \\
\text { (qualitativo)(*) }\end{array}$ & \begin{tabular}{l}
\multicolumn{2}{c}{ Vantagens } \\
Uso geral em \\
qualquer segmento \\
produtivo
\end{tabular} & \begin{tabular}{l}
\multicolumn{3}{c}{ Limitaçöes } \\
Indicam apenas a \\
existência de estudos \\
na área de \\
prevenção ou \\
minimização
\end{tabular} & $\begin{array}{l}\text { Exemplos } \\
\text { Estudos para } \\
\text { reciclagem de oleo\% } \\
\text { de veículos que } \\
\text { utilizam este tipo de } \\
\text { oleo }\end{array}$ \\
\hline $\begin{array}{l}\text { Baseado em } \\
\text { atividades(semi } \\
\text { qualitativo) }\end{array}$ & $\begin{array}{l}\text { Atuação direta em } \\
\text { procedimentos e } \\
\text { equipamentos de } \\
\text { qualquer area } \\
\text { Oferecem mais } \\
\text { detalhes e podem } \\
\text { medir a eficiência da } \\
\text { operação }\end{array}$ & $\begin{array}{l}\text { Grande manuseio de } \\
\text { dados, mesmo } \\
\text { quando tecnicamente } \\
\text { simples } \\
\text { Possibilidade de } \\
\text { falhas nas medições } \\
\text { e custo elevado para } \\
\text { obtenção de dados }\end{array}$ & $\begin{array}{l}\text { Freqüencia de limpeza } \\
\text { de tanques } \\
\text { Substituiçaao de } \\
\text { produtos } \\
\text { Volume de material } \\
\text { reciclado } \\
\begin{array}{l}\text { Volume de material } \\
\text { tratado } \\
\text { Soda gasta }\end{array}\end{array}$ \\
\hline $\begin{array}{l}\text { Baseado em } \\
\text { concentração (quantit }\end{array}$ & $\begin{array}{l}\text { Possibilitam medida } \\
\text { da performance }\end{array}$ & $\begin{array}{l}\text { Custo elevado. } \\
\text { grande número de } \\
\text { amostragens e } \\
\text { análises }\end{array}$ & $\begin{array}{l}\text { Acompanhamento de } \\
\text { cromo em descarga de } \\
\text { água de refrigeração }\end{array}$ \\
\hline $\begin{array}{l}\text { Baseado em } \\
\text { eficiência } \\
\text { normalizada (quantita }\end{array}$ & $\begin{array}{l}\text { Permite a } \\
\text { comparação } \\
\text { plantas }\end{array}$ & $\begin{array}{l}\text { Risco de simplificar } \\
\text { uma situação }\end{array}$ & $\begin{array}{l}\text { 1- Por } \\
\text { atividadem } 3 / \mathrm{m} 3 / \text { ano } \\
\text { (vazam) } \\
2 \text { - Produçãoft } 3 / \text { barrilla } \\
\text { (cont) } \\
\text { 3- Por geraçãom } 3 / \mathrm{m} 3 \\
\text { (perda) }\end{array}$ \\
\hline
\end{tabular}

(*) Conforme regulamento da EPA, empresa que gerar uma quantidade de rejeito superior a $1000 \mathrm{~kg} / \mathrm{ano}$ deverá estar desenvolvendo programas para sua minimização (volume e toxidez). 


\section{PRODUÇÃO}

caso da indústria de petróleo temos:

- Carga Poluente em Efluente Hídrico (CPEH) - visa medir a quantidade de poluente de efluente hídrico lançada no corpo receptor, no mês.

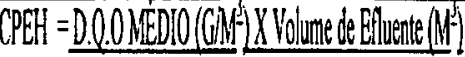 Caryg Processadal(M)}

(D.Q.O - Demanda Química de Oxigênio)

-Índice de Energia (IE) - Indica o consumo unitário de energia sem levar em conta a complexidade de cada órgão.

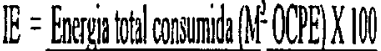

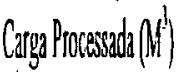

(OCPE- óleo combustivel em peso equivalente)

A energia total consumida corresponde ao somatório de toda a energia convertida em $\mathrm{m}^{3}$ de óleo combustível. A energia elétrica comprada é convertida com o fator $0,273 \mathrm{~m}^{3}$ de OCPE/Mwh.

\section{2 - Indicadores do Estado do Meio Ambiente}

Esta área cobre as condições do meio ambiente no momento da avaliação, ou seja, não representa apenas as cargas de rejeitos porém a identificação da sua influência em possíveis alterações ambientais, independentemente de outras organizações próximas. Sua finalidade é identificar problemas ambientais, objetivando sua melhoria e auxiliando o processo de tomada de decisão, respondendo aos seguintes questionamentos:

- O que aconteceu com o estado do meio ambiente ou dos recursos naturais?

- Porque isto ocorreu?

- O que está sendo feito?

Para o primeiro questionamento, temos os indicadores de tendência fisica ou biológica; no segundo, os indicadores de "stress" ou de pressão e, no último, as medidas e a política adotada.

Como exemplos temos:

\begin{tabular}{|l|l|l|l}
\hline \multicolumn{1}{|c|}{ Itens } & \multicolumn{1}{|c|}{ Pressão } & \multicolumn{1}{|c}{ Estado } & \multicolumn{1}{c}{ Resposta } \\
\hline $\begin{array}{l}\text { Alterações } \\
\text { climáticas }\end{array}$ & Emissões & Concentraçōes & Medidas ambientais \\
\hline Acidificação & (SOX,NOX,NH3) & Deposição, concent. & Investimentos \\
\hline Degradaçãó do solo & $\begin{array}{l}\text { Alteração no uso do } \\
\text { solo }:\end{array}$ & $\begin{array}{l}\text { Perda da camada } \\
\text { superior }\end{array}$ & $\begin{array}{l}\text { Reabilitação, } \\
\text { proteção }\end{array}$ \\
\hline Florestas & Intensidade do uso & Área degradada & Áreas de proteção \\
\hline Índice ambiental & $\begin{array}{l}\text { Índice de pressão } \\
\text { Índice de estado }\end{array}$ & Índice de resposta \\
\hline
\end{tabular}




\section{PRODUÇÃO}

\section{3 - Indicadores Gerenciais}

Sistemas gerenciais incluem todos os procedimentos $\mathrm{e}$ atividades relacionadas com a organização, planejamento, alocação de recursos, controle operacional de processo, "feedback" e verificação dos resultados da performance.Identificam a raiz de possíveis deficiências, mostrando o progresso da organizaçãopara atender os alvos estabelecidos para melhoria ambiental. Para elaboração destes indicadores temos: indicadores de satisfação e comportamento de partes interessadas/observadores, indicadores financeiros etc..

Neste segmento, um aspecto importante deve ser definido, qual seja, a identificação das denominadas partes interessadas ou observadores. Podemos separá-los em três grupos a saber:

-Financeiros - Banqueiros, investidores, empregados, fornecedores e compradores. Neste segmento, o foco principal está na quantificação dos custos ambientais e quais os planos para sua redução, nos custos de externalidades decorrentes de reclamações ou multas por órgãos fiscalizadores, no custo de iniciativas positivas, no custo de atendimento às legislações locais e nas evidências de um bom gerenciamento ambiental, concorrendo para vantagens comerciais.

Não financeiros - Profissionais que avaliam a empresa, fornecendo as licenças para operação, a comunidade local, os grupos ambientais, futuros empregados, seguradoras. Neste setor, as partes interessadas tendem a ser positivas, forçando as empresas a tomarem atitudes pró ativas quanto ao gerenciamento ambiental, estando mais preocupadas com danos locais do que com os globais . O foco das atenções recai na análise dos riscos, na externalização ou internalização dos custos ambientais, nas ocorrências operacionais com dano ambiental, em dados quantitativos das descargas, ou seja, na identificação de falhas que podem gerar danos à imagem da empresa.

Representantes da sustentabilidade Neste campo, o sistema de avaliação da performance ambiental deverá demonstrar que as atividades da organização não excedem as cargas ambientais críticas, pondo em risco a sustentabilidade. Como observadores destes indicadores temos:

Internos à empresa : Gerência da empresa,à área de desenvolvimento de produto e processo, à fabricação etc..

Externos à empresa : o Mercado (publicidade), os auditores ambientais (multas), etc.

Como exemplo temos:

Indicador de atendimento à legislação (\%C) representando a percentagem de atendimentos em uma planta numa base mensal e anual.

$\% \mathrm{C}=\left(\mathrm{T}_{\mathrm{s}}-\mathrm{E}_{\mathrm{s}} / \mathrm{T}_{\mathrm{s}}\right) * 100$

Onde:

$\% \mathrm{C}=$ Percentagem de atendimento

$\mathrm{T}_{\mathrm{s}}=$ Número de amostras para $\mathrm{o}$ período reportado

$\mathrm{E}_{\mathrm{s}}=$ Total de amostras que ultrapassam o permitido 


\section{PRODUÇÃO}

Indicador de custo de atendimento, podendo ser representado de duas formas:

Como percentual das vendas (COC)

$\mathrm{COC}=\frac{\text { Gastos Ambientais }}{\text { Total das Vendas }} * 100$

Como custo por unidade de produção

$\mathrm{COC}=\frac{\text { Gastos ambientais }}{\text { Total produzido }}$

\section{4- Problemas Práticos no Desenvolvimento e na Apresentação de Índices de Performance Ambiental}

a. Em se tratando de geração de indicadores de performance ambiental, alguns cuidados devem ser considerados, a saber: tipo de dados a utilizar; que podem ser: absolutos (ex: $\mathrm{SO}_{2}$ /ano), relativos ou compostos (energia/unidade), agregados (total rejeito disposto, incinerado), indexados (equivalente, etc...), qualitativos, ponderados, etc..

b. De uma forma geral, os seguintes critérios devem ser observados quanto à identificação de um índice de performance ambiental: ter validade cientifica, ser representativo, apresentar resposta a alterações, ser preditivo, ser limitante (alvo), apresentar potencial para comparação, baixo custo, apresentar adequação dos dados, ter disponibilidade de dados, ser relevante para cada platéia (acionistas, empregados, comunidade), ser claro, ser analítico (confiável para uma medida precisa e acurada), ser consistente com os objetivos ambientais.

c. Quanto à comunicação, consideramse dois aspectos: interno ao processo e externo. No primeiro caso, indicadores relacionados com o re-uso, reciclagem e relacionados com a prevenção(por exemplo, prever quanto a vazamentos, etc.), que envolvem a operação na responsabilidade de minimizá-los, apresentam boa receptividade junto à equipe.

No caso de indicadores para divulgação externa ao processo, conforme apresentado no artigo "Some Practical Problems in Developing and Presenting Environmental Quality Indexes to the Public"(L.Edwin Coate and Anthony K.Mason-Proc.Int.Conf.on Environmental Searching and Assessment, 1975, pp 31-2 -31-3), os seguintes aspectos devem ser considerados:

- Concordância na definição de índice e meio ambiente - identificar público alvo.

- Quem irá analisar a informação.

- Fontes dos dados ( atendimento às normas, dados sobre emissões e efluentes)

- Análise de custo e beneficio (efetividade)

\section{5 - Visão de Futuro}

Analisando a literatura sobre os sistemas de genciamento ambiental [Wainman \& kydd, 1994], observamos uma tendência em relacionar o gerenciamento ambiental com 


\section{PRODUÇÃO}

qualidade e segurança o que irá provocar a necessidade e o desenvolvimento de uma função gerencial com esta visão.

No campo da normalização, acompanhamos o projeto de norma inglesa (BS 8750) relativo a sistemas de segurança e meio ambiente, que poderá servir de base para uma fusão das normas de qualidade (série ISO 9000 ) com as normas ambientais (série ISO 1400), criando um único sistema envolvendo qualidade, segurança e meio ambiente.

\section{Referências Bibliográficas}

BJRN W. Environmental Management - A chalenge to Industry., proceedings of the 14th World Petroleum Congres, 1994, Jolnn Wiley \& Sons, pp $337-343$

WAINMAN e KYDD. The Environmental Manual for Business and Professionals, Ed Dwight Wainman, CA, 1994

RAPPORT, D. J. Evolution of Indicator of Ecosistem Healt., Ecological Indicators, vol -1, Elsevier Applied Science, 1990pp-121-134

HOPE, C. e PARKER, J. Environmental information for all. The need for a montly index Energy Policy, May 1990 pp 312 - 319

KÓS, M. Informativo da ABIQUIM, Comissão do Atuação Responsável, 1994 rev 3 .

ISO/TC207/SC4 WD 14031.1 Guidelines on Environmental
Performance Evaluation. February 10,1995

Environmental Performance Indicators: Methods for Measuring Pollution Prevention., API publication, September, 1994

THOMAS, W. A. Indicators of Environmental Quality, Plenum Press, NY, 1972.

INHABER, H.. Environmental Indices , John Wikey \& Sons Canada , 1974.

OTT, W. R. Environmental Indices Theory and Practice, Ann Arbour Science, 1978

HUSALKER, C.T. E CARPENTER, D.E. Environmental Monitoring and assessement program: Ecological Indicator, , Environmental Protection Agency (EPA) Atmospheric Research and Exposure Assessement lab, 1990.

BILLING, R.C. et alli. Reporting on Environmental Performance, The Canadian Institute of Chatered Accountants, 1994,

HAINES, R. W. Environmental Performance Indicators: Balancing Compliance With Business Economics, TQEM, Summer 1993, pp367 - 373

FENN, S. Recent Study Shows Wide Variation in Major Corporation' Environmental Performance., Investor Responsability Research Center Inc.(IRCC). 


\section{PRODUÇÃO}

NAIMON, J. S. Benchmarking and Environmental Trend Indicators., TQEM Spring 1994, 269 - 280.

GREENBERG, R. S. e UNGER, C. A. TQM and the Cost of Environmental Quality, TQEM, Winter 1991/92, pp97 102.

INHABER, H. Environmental Quality: Outline for a national index for Canada., Ekistics 243, Feb, 1976, pp 102 $-10$

HAMMOND, A.; ADRIAANSE, A; RODENBURG, E. Environmental Indicators: A Systematic Approach on Environmental Policy Performance in Context of Sustainable Development. WRI, May 1995 